\title{
Anterior Cruciate Ligament Rupture and Concomitant Injuries \\ ORIGINAL
}

\section{Abstract}

Introduction: The association between previous injury and the risk of re-injury has been widely studied, however still there are limited studies about the prevalence and distribution of the injuries associated to rupture of Anterior Cruciate Ligament ( $A C L)$ mainly focused on people who plays sports for leisure or to improve their quality of life.

Objective: To identify the prevalence of concomitant injuries with rupture of $A C L$ and its association with sex, age and practice of sports for leisure.

Methods: Cross-sectional study of clinical base. It was analyzed the data of clinical records and demographic information of 807 individuals who underwent $A C L$ reconstruction surgery in a clinic specializing in orthopedics knees in Santo André, São Paulo, Brazil.

Results: The prevalence of concomitant injuries with the $A C L$ injury was $57.9 \%$. The meniscus injuries were the main concomitant injuries found. It is observed a trend of concomitant injuries with ACL rupture in males (59.2\%) and in individuals who do not practice recreational sports (58.9\%). Individuals who had concomitant lesions had higher median age (37\%, 95\% Cl 36-39) compared to individuals diagnosed with isolated $A C L$ rupture.

Conclusions: The prevalence of concomitant injuries with the $A C L$ rupture found in this study points to the need of further research about injuries of adjacent structures to ACL.

\section{Keywords}

Anterior Cruciate Ligament; Ligaments; Knee Injury.
Francisco Winter dos Santos Figueiredo $0^{1,2,6}$, Laércio da Silva Paiva1,2,6, Luiz Vinicius de Alcantara Sousa ${ }^{1,2,6}$,

Maria Inês da Rosa ${ }^{5}$, Luciane Bisognin Ceretta ${ }^{5}$, Vitor Engrácia Valenti ${ }^{2,3}$, Luciano Miller Rodrigues ${ }^{2}$, Blanca Elena Guerrero Daboin ${ }^{2,4}$,

Italla Maria Pinheiro Bezerra², Luiz Carlos de Abreu ${ }^{2,7}$, Fernando Adami 1,2,5,6

1 Faculdade de Medicina do ABC. Laboratório de Epidemiologia e Análise de Dados do Departamento de Saúde Coletiva. Santo André, SP, Brasil.

2 Faculdade de Medicina do ABC. Laboratório de Delineamento de Estudos e Escrita Científica do Departamento de Saúde Coletiva. Santo André, SP, Brasil.

3 Programa de Graduação em Fisioterapia, Faculdade de Ciências e Tecnologia da UNESP. Rua Roberto Simonsen, 305 19.060-900. Presidente Prudente, São Paulo, Brasil.

4 Universidade do Zulia, Maracaibo, Venezuela.

5 Universidade do Extremo Sul Catarinense, Programa de Pósgraduação em Saúde Coletiva, Criciúma, SC, Brazil.

6 Instituto Brasileiro de Ensino e Pesquisa Aplicada - IBESPA.

7 Harvard T.H. CHAN School of Public Health. Department of Environmental Health, 665 Huntington Avenue, Boston, MA 02115

\section{Contact information:}

\section{Fernando Adami.}

Address: Av., Príncipe de Gales, CEP 09060650, Santo André, São Paulo, Brasil. Tel: +55 (11) 96062-0133. 


\section{Introduction}

The anterior cruciate ligament $(\mathrm{ACL})$ is a major contributor to the stabilization of the knee [1] and so it's constantly injured [2], with an incidence of 0.8 cases per 1,000 inhabitants in individuals 10-64 years [3]. The rupture of this ligament commonly cause degeneration of other intrinsic knee structures as a consequence of post injury instability [4] and so articulate cartilage injuries are often encountered at the time of $A C L$ reconstruction [5].

The association between previous injury and the risk of re-injury has been widely studied [6]. Many studies have been published examining risk factors for ACL injuries or determining an association with sports practice or sex $[7,8]$ or association of risk factors in the outcome of $A C L$ reconstruction $[9,10]$ but still there are few studies about the prevalence and distribution of the injuries associated to rupture of $A C L[4,11]$ especially focused on people who plays sports for leisure.

Therefore, the objective of this study is to identify the prevalence of concomitant injuries with rupture of $A C L$ and its association with sex, age and practice of sports for leisure.

\section{Materials and methods}

Cross-sectional study of clinical base with 807 individuals who underwent Anterior Cruciate Ligament reconstruction surgery in a clinic specializing in orthopedics knees in Santo André, São Paulo, Brazil, between January 2006 and December 2011. The study was approved by the Research Ethics Committee of the Health Department of Santo André, São Paulo, Brazil under Nº. 022/2011.

The Data was obtained from 900 clinical records, but patients who had relapsing injury ( $n=$ 38) or who choosed not to take the exam ( $n=$ 55) were excluded. Thus, we analyzed 807 charts with sociodemographic and clinical information, which extracted variables were sex, operated knee, sports practice in the period of the injury, presence and types of injuries diagnosed by physical examination and confirmed by Magnetic Resonance Imaging (MRI).

The quantitative variables were described by median and confidence interval; the categorical variables by absolute and relative frequency. To evaluate the relationship between the presence of associated injuries and sex, sports and leisure, we used chisquare test. To compare the age of individuals with or without associated injuries was used the KruskalWallis test due to non-normality of the data (Shapiro-Wilk test, $p<0.05)$. The confidence level adopted was $5 \%$. The data was analized using the statistical software Stata 11.0.

\section{Results}

There were studied 807 individuals (691 men and 116 women) with first Anterior Cruciate Ligament $(A C L)$ injury diagnosed by Magnetic Resonance Imaging (MRI) who had a median age of $35[95 \% \mathrm{Cl}$ 27-44). Of those, $57.9 \%(n=467)$ had in addition other associated $A C L$ injuries.

Individuals with concomitant injuries to $A C L$ injury were mostly male $(87.6 \%, n=409)$, who did not practice sports for leisure $(73.2 \%, n=342)$. The main damages associated with $A C L$ rupture were observed with greater frequency in the medial meniscus (54.6\%) in the lateral meniscus (40.0\%) and osteochondral lesions (14.1\%) (Figure 1).

It is observed a tendency to higher prevalence of concomitant injuries to the $\mathrm{ACL}$ rupture in males $(59.2 \%, n=409)$, most in those who not play sports for leisure (58.9\%, $n=342$ ) (Table 1).

The age of the individuals who had concomitant injuries with $A C L$ rupture was higher than those who had isolated ACL with a median of 37 [95\% Cl 36-39) and 32 (95\% Cl 31-34) respectively, a statistically significant difference $(p<0.001)$ (Figure 2 ). 
Figure 1: Characterization of groups and distribution of injuries associated with rupture of anterior cruciate ligament in 807 individuals elected to ligament reconstruction surgery, Santo André, Brazil, 2006-2011.

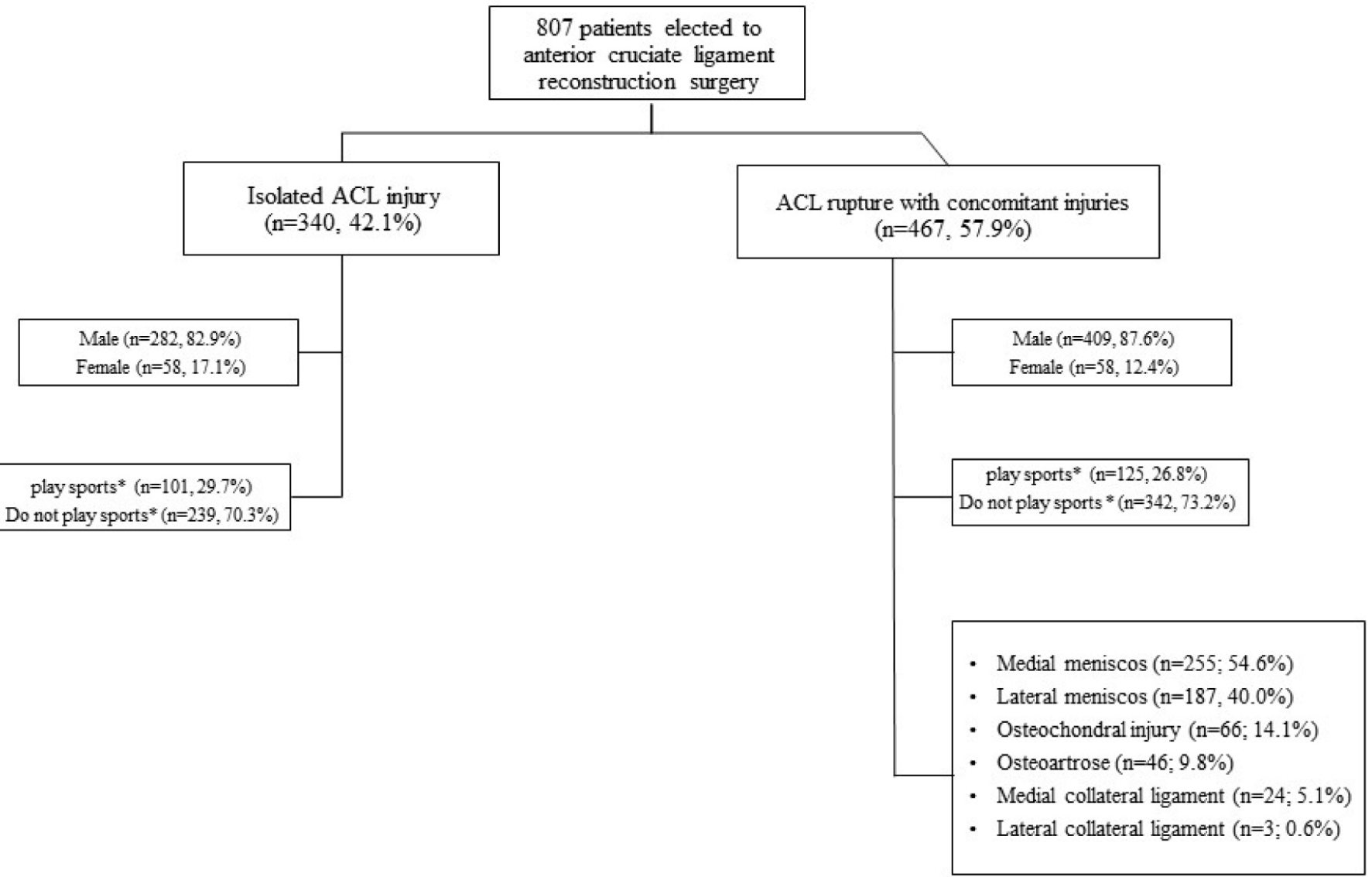

* Play Sports for leisure

Figure 2: Median (C195\%) of age of individuals diagnosed with isolated anterior cruciate ligament rupture $(A C L)$ and individuals diagnosed with concomitant injuries to $A C L$ rupture, Santo André, Brazil, 2006-2011.
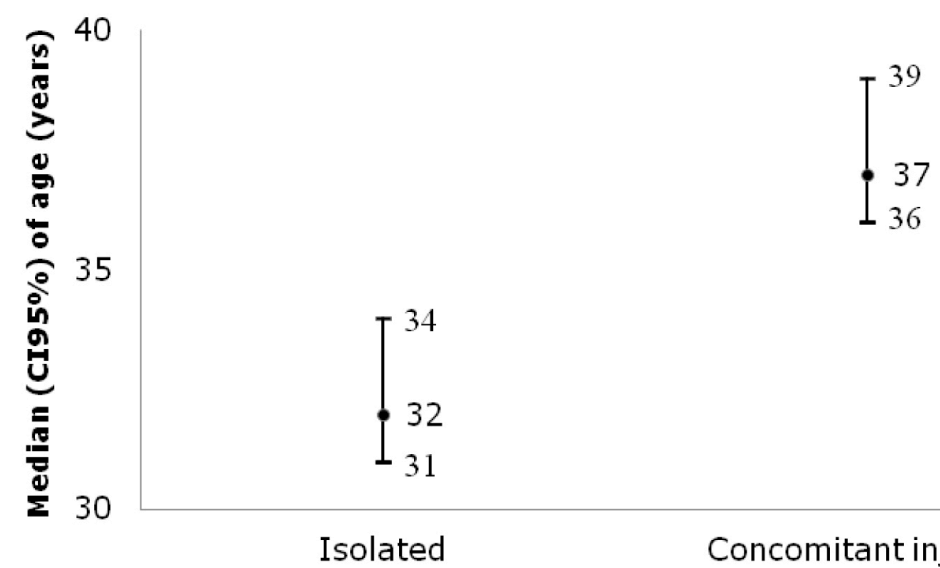

(Mann-Whitney, $p<0.001$ ) 
Table 1. Concomitant injuries to the anterior cruciate ligament rupture by sex and sports for leisure in 807 individuals elected to ligament reconstruction surgery, Santo André, Brazil, 2006-2011.

\begin{tabular}{|c|c|c|c|}
\hline \multirow{2}{*}{ Characteristics } & \multicolumn{2}{|c|}{ ACL injury with concomitant injury $n(\%)$} & \multirow{2}{*}{$\mathbf{p}^{*}$} \\
\hline & Yes & No & \\
\hline \multicolumn{4}{|l|}{ Sex } \\
\hline Male & $409(59.2)$ & $282(40.8)$ & \multirow{2}{*}{0.064} \\
\hline Female & $58(50.0)$ & $58(50.0)$ & \\
\hline \multicolumn{4}{|l|}{ Play sports for leisure } \\
\hline Yes & $125(55.3)$ & $101(44.7)$ & \multirow{2}{*}{0.359} \\
\hline No & $342(58.9)$ & $239(41.1)$ & \\
\hline
\end{tabular}

\section{Discussion}

Initially, our first hypothesis was that the prevalence of concomitant injuries with Anterior Cruciate Ligament $(A C L)$ rupture in addition to the association with female $[8,9]$ was associated with play sports for leisure and aging.

By identifying the prevalence of concomitant injuries to the $A C L$ injury and its relation to sex, play sports as leisure and age of the individuals, the main findings were: i) the prevalence of concomitant lesions was 57.9\%; ii) the meniscus injury was the main found concomitant injury; iii) there was no association of the prevalence of concomitant injuries to $A C L$ injury by gender or play sports for leisure; iv) individuals with concomitant injury are older compared to those who were diagnosed with isolated $\mathrm{ACL}$.

The ACL injury is associated with other injuries of the lower limbs [6] and its association with the practice of professional sports $[2,12,14,15]$ and female [16]. In addition, a variety of factors may contribute to cartilage damage, including the effects of altered tibiofemoral biomechanics as well as new traumatic injury resulting from recurrent episodes of instability [5].

The prevalence found in this study related to those individuals who plays sports for leisure was approximately found by Walden et al. [4] in professional athletes. This is due the higher risk of injury to other knee structures after a ACL injury [17] mainly in the meniscus [11], which alerts to prevent injuries even in those who does not play sports professionally.

The injury meniscus was the main concomitant lesion found in this study and has a prevalence of $41 \%$ to $82 \%$ [3], this may arise as a result of instability of the knee after the injury and may recur if the instability remains [18].

The prevalence of associated injuries did not differ between the sexes, however there was found a higher proportion of associated injuries in males, which can be explained by the association between increased thickness articular cartilage and $A C L$ injury in males [2] although the causes of injuries in men and women are multifactorial [13].

The higher prevalence of injuries in females is attributed to biomechanical and structural factors $[4,8,15]$ that result in worse outcomes of injuries before $A C L$ reconstruction surgery when compared to men [3].

The no association between prevalence of injuries associated with ACL rupture related to those individuals who plays sport for leisure found in this study should be viewed with caution because the population does not consist of professional athletes. In professional athletes who practice high level sports with overload knee the risk of injury may increase and consequently the prevalence of associated injuries $[7,19]$. 
In this study, the age of the individuals associated with lesions was higher than those with only $\mathrm{ACL}$ injury. Meniscal lesions, cartilage and osteoarthritis has degenerative pathophysiology, so that over the years the body has to adapt to the abnormal mechanical stress by transfer loads, and during that traumas those injuries may appear more easily and are related to aging $[20,21,22]$.

Therefore, research should be developed in order to deepen about health care, considering the importance of understanding from the reablitação know the prevalence of patients. Research should be implemented to give visibility to situations like these, however, while in Brazil the scientific production has been increasing significantly increase with the proper training of health professionals who work with research in project management. $[23,24]$

It is known that there are several limitations in this study. The largest proportion of non- leisure for sport practitioners found in this study may indicate an inverse association between related injuries and not playing sports, because you can not establish causality due to the absence of temporality and monitoring of cross-sectional studies. In addition, the association between concomitant injuries and injured knee can not be performed due to lack of information of the dominant limb.

\section{Conclusions}

The prevalence of concomitant injuries to the anterior cruciate ligament injury found in this study points to the need for further investigation of injury to adjacent structures to the anterior cruciate ligament in patients with injurie in this ligament in order to implement more appropriate therapeutic practices before and after the surgery. In addition, there is a need for researching on causality between sports for leisure and concomitant injuries to the ACL.

\section{Funding}

None.

\section{Conflict of interest}

None.

\section{References}

1. Ardern CL, Webster KE, Taylor NF, Feller JA. Return to sport following anterior cruciate ligament reconstruction surgery: $A$ systematic review and meta-analysis of the state of play. $\mathrm{Br} \mathrm{J}$ Sports Med. 2011; 45: 596-606

2. Rotterud JH, Sivertsen EA, Forssblad M, Engebretsen L, Aroen A. Effect of gender and sports on the risk of full-thickness articular cartilage lesions in anterior cruciate ligament-injured knees: A nationwide cohort study from sweden and norway of 15783 patients. Am J Sports Med. 2011; 39: 1387-1394

3. Ageberg E, Forssblad M, Herbertsson P, Roos EM. Sex differences in patient-reported outcomes after anterior cruciate ligament reconstruction: Data from the swedish knee ligament register. Am J Sports Med. 2010; 38: 1334-1342

4. Walden M, Hagglund M, Magnusson H, Ekstrand J. Anterior cruciate ligament injury in elite football: A prospective threecohort study. Knee Surg Sports Traumatol Arthrosc. 2011; 19: 11-19

5. Brophy RH, Zeltser D, Wright RW, Flanigan D. Anterior cruciate ligament reconstruction and concomitant articular cartilage injury: Incidence and treatment. Arthroscopy. 2010; 26: 112-120

6. Fulton J, Wright K, Kelly M, Zebrosky B, Zanis M, Drvol C, et al. Injury risk is altered by previous injury: A systematic review of the literature and presentation of causative neuromuscular factors. Int J Sports Phys Ther. 2014; 9: 583-595

7. Borchers JR, Pedroza A, Kaeding C. Activity level and graft type as risk factors for anterior cruciate ligament graft failure: A casecontrol study. Am J Sports Med. 2009; 37: 2362-2367

8. Prodromos CC, Han Y, Rogowski J, Joyce B, Shi K. A metaanalysis of the incidence of anterior cruciate ligament tears as a function of gender, sport, and a knee injury-reduction regimen. Arthroscopy. 2007; 23: 1320-1325.e1326

9. Hirota, VB, França, E, Paulo, LF.L, Ayala, CO. Adami, F. Goal's Orientation of Brazilian's Military Police Cadets. Sch. J. Arts. Humanit. Soc. Sci. 2014; 2(5C): 779-781.

10. Barrett AM, Craft JA, Replogle WH, Hydrick JM, Barrett GR. Anterior cruciate ligament graft failure: A comparison of graft type based on age and tegner activity level. Am J Sports Med. 2011; 39: 2194-2198

11. Faltstrom A, Hagglund $M$, Magnusson $H$, Forssblad $M$, Kvist J. Predictors for additional anterior cruciate ligament reconstruction: Data from the swedish national acl register. Knee Surg Sports Traumatol Arthrosc. 2014 
12. Rocha IDd, Moraes TMdS, Rezende MUd, Pécora JR. Avaliação da evolução de lesões associadas à lesão do ligamento cruzado anterior. Acta Ortopédica Brasileira. 2007; 15: 105-108

13. Kilcoyne KG, Dickens JF, Haniuk E, Cameron KL, Owens BD. Epidemiology of meniscal injury associated with acl tears in young athletes. Orthopedics. 2012; 35: 208-212

14. Kluczynski MA, Marzo JM, Bisson LJ. Factors associated with meniscal tears and chondral lesions in patients undergoing anterior cruciate ligament reconstruction: A prospective study. Am J Sports Med. 2013; 41: 2759-2765

15. Luciano, A P; Filho, N F ; Adami, F; Abreu, L C . Fratura por estresse segmentária na tíbia em corredora recreacional. Revista brasileira de ortopedia (impresso), v. 48, p. 574-577, 2013.

16. Quisquater L, Bollars P, Vanlommel L, Claes S, Corten K, Bellemans J. The incidence of knee and anterior cruciate ligament injuries over one decade in the belgian soccer league. Acta Orthop Belg. 2013; 79: 541-546

17. Brito J, Soares J, Rebelo AN. Prevenção de lesões do ligamento cruzado anterior em futebolistas. Revista Brasileira de Medicina do Esporte. 2009; 15: 62-69

18. Yan D, Song $Y$, Pei F. Allograft ligament transplantation in anterior cruciate ligament reconstruction patients with meniscal tears. Arch Orthop Trauma Surg. 2014; 134: 521-527

19. Paulo, L.F.L. Andrade, M.F.A.M. Neto, C.B. Hirota, V.B. Adami, F. Prevalência de dor em alunos da academia de polícia militar do barro branco. Revista ENAF Science | Volume 9 - No $01 \mid 1^{\circ}$ Semestre de 2014

20. Bae JY, Park KS, Seon JK, Kwak DS, Jeon I, Song EK. Biomechanical analysis of the effects of medial meniscectomy on degenerative osteoarthritis. Med Biol Eng Comput. 2012; 50: 53-60

21. Brandt KD, Dieppe P, Radin EL. Commentary: Is it useful to subset "primary" osteoarthritis? A critique based on evidence regarding the etiopathogenesis of osteoarthritis. Semin Arthritis Rheum. 2009; 39: 81-95.

22. Lopes, AD, Costa LO, Saragiotto BT, Yamato TP, Adami F, Verhagen E. Musculoskeletal pain is prevalent among recreational runners who are about to compete: an observational study of 1049 runners. J. Physiother. 2011; 57(3): 179-82

23. Bezerra IMP, et al. Professional activity in the context of health education: a systematic review. Journal of Human Growth and Development. 24(3): 255-262. doi.org/10.7322/jhdg.88909

24. Monteiro CBM, Almeida Junior AD, Wajnzstejn R. Project Management in Health and Medical Research. Journal of Human Growth and Development. 2014; 24(3): 239-242. DOI: dx.doi.org/10.7322/jhdg.88895

\section{Comment on this article:}

\section{8 in $8+\mathbf{S} P$}

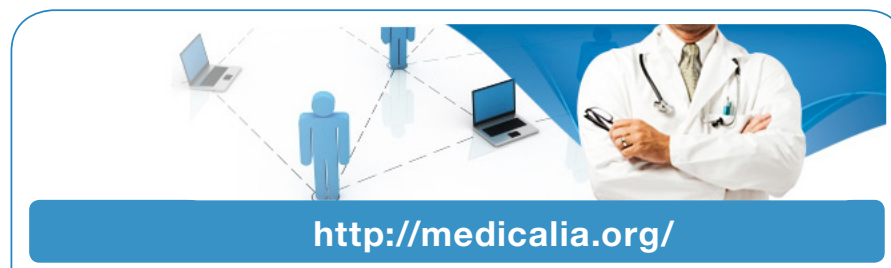

Where Doctors exchange clinical experiences, review their cases and share clinical knowledge. You can also access lots of medical publications for free. Join Now!

\section{Publish with iMedPub}

http://www.imed.pub

International Archives of Medicine is an open access journal publishing articles encompassing all aspects of medical science and clinical practice. IAM is considered a megajournal with independent sections on all areas of medicine. IAM is a really international journal with authors and board members from all around the world. The journal is widely indexed and classified Q1 in category Medicine. 